\title{
Comments about Urban Bioclimate Aspects for Consideration in Urban Climate and Planning Issues in the Era of Climate Change
}

\author{
Andreas Matzarakis 1,2 (iD) \\ 1 Research Centre Human Biometeorology, Deutscher Wetterdienst, Stefan-Meier-Str. 4, \\ D-79104 Freiburg, Germany; andreas.matzarakis@dwd.de \\ 2 Chair of Environmental Meteorology, Institute of Earth and Environmental Sciences, \\ Albert-Ludwigs-University Freiburg, 79085 Freiburg, Germany
}

check for updates

Citation: Matzarakis, A. Comments about Urban Bioclimate Aspects for Consideration in Urban Climate and Planning Issues in the Era of Climate Change. Atmosphere 2021, 12, 546. https://doi.org/10.3390/atmos12050546

Received: 9 April 2021

Accepted: 20 April 2021

Published: 24 April 2021

Publisher's Note: MDPI stays neutral with regard to jurisdictional claims in published maps and institutional affiliations.

Copyright: (C) 2021 by the author. Licensee MDPI, Basel, Switzerland. This article is an open access article distributed under the terms and conditions of the Creative Commons Attribution (CC BY) license (https:// creativecommons.org/licenses/by/ $4.0 /)$.
In the era of climate change, before developing and establishing mitigation and adaptation measures that counteract urban heat island (UHI) effects [1], city planners and administration authorities need to receive effectively communicated information regarding the spatial and temporal dimensions of meteorological and climatological conditions in a city. Such information also includes microscale options, which are directly related to ensuring human health and welfare [2,3].

Due to climate change, the mean air temperature is expected to increase, and heat waves are assumed to become more frequent, intense and longer [4]. For cities [5], this means that its inhabitants experience climate change twofold, on one hand, by UHI effects, and on the other, by the already unfolding impacts of climate change [6]. Therefore, there is an increased demand of planners and architects for the assessment and quantification of adaptation measures. These responses include, amongst others, approaching specific urban morphological compositions, and the implementation of different types of vegetation that can improve the local urban climate.

Urban areas, with their artificial materials and specific morphology, act as a "disturbance" to the atmosphere, altering its physical conditions that dramatically modify energy exchange dynamics, and the delicate equilibrium of urban chemical compositions $[7,8]$. The modified energy fluxes generate an urban-rural thermal contrast known as the urban heat island, which is the most widely known effect of cities on the atmosphere. The UHI, and its intensity oscillation, can be described by the urban-rural surface, not only in terms of air and surface temperatures but also via human thermal comfort indices [9]. The intensity of UHI depends on not only meso-scale factors, such as the size, population density and land use of a city, but also on microscale factors, such as building ratio and vegetation coverage/distribution $[7,8,10,11]$. The UHI is most pronounced during the night time. The strongest influencing factors are the radiation trapping by urban structures, and the reduced possibility of radiation emission to the encircling free atmosphere. Another factor is the increased storage of heat by artificial surfaces and the emission of heat during the night. Inaddition to the reduced evaporation, which affects the surface energy partition through reduced cooling. In addition to the quantification and explanation of UHI as a result of any given type of edified urban structure, UHI can and should be approached via its unambiguous impacts upon the quantification of heat stress on humans for different time and spatial scales, particularly at microscales [12].

The following suggestions, possibilities and remarks should be seen as a starting point to incentivize further discussion and exploration. Only examples and some points of interest are described and are not comprehensive.

There is a difference between the analysis and quantification of the effects of modifications of cities (and their influence on atmospheric factors) and the effects upon urban inhabitants, which are highly diverse [13]. Approaches focusing on energetic aspects can 
cover the use of energy or modification in meteorological factors, such as air temperature and humidity $[7,8,14]$.

Concerning urban bioclimate, it is clear that the target is exactly defined, i.e., the prevailing health and welfare of humans [13]. Such awareness should, moreover, be associated with the mitigation aspects of urban areas, in addition to the acknowledgement that urban areas are responsible for more than $75 \%$ of the emissions and host the overall concentration of human beings [6]. Following this line of reasoning, it is imperative to remember that while urban fabric presents negative attributes in terms of its specific climate conditions, it adjacently continues to host many positive socio-economic and cultural elements, which must be preserved [11,13].

Most of the recent studies on mitigation and adaptation strategies focus on the reduction of air temperature in urban areas facing climate change. These studies recurrently propose changes of surface materials and an increase of "greenery" in cities. In addition, several studies analyze human thermal comfort levels, which has to be the main target for city planners and decision makers. This kind of study focuses on the integral effect of air temperature, air humidity, wind speed and radiation fluxes on humans within a city [15]. For this reason, the quantification of the spatial and temporal distribution of the UHI, as well as the assessment of mitigation and adaptation measures, has to be considered and applied carefully [16]. Human biometeorological conditions should be integrated. However, this consideration should not only be confined to presenting mean conditions, but just as importantly the consideration should be acknowledged in terms of their frequencies (e.g., number of days, hours per year or season) [17]. Currently, the most urgent issue is the quantification of heat stress and its reduction through the implementation of planning measures, especially in the light of the ensuing climate change effects that are already being felt within urban fabric [18].

For the quantification of the effects on humans, an integral approach based on human biometeorological methods is required, which has several options and advantages. First, maps with specific resolutions for whole cities or specific parts can be created in order to detect hot spots with higher thermal levels and/or risk factors [2,19]. Second, specific areas (with high political and environmental pressure) can be analyzed to determine which would be the best configuration of the surfaces, aspect ratios or orientations of trees and buildings [20,21]. Third, different materials and their properties can be simulated within models to quantify their respective effect upon an encircling microclimate. Finally, climate change simulations can be helpful when analyzing the factors which are affecting the urban climate in future timeframes [3,16,22]. The human body does not have any selective sensors for the perception of individual climatic parameters. It can, therefore, only feel the effect of all parameters together. The application of thermal indices based on the human energy balance gives detailed information on the effect of complex thermal environments on humans. It is related to the close relationship between the human thermoregulatory mechanism and the human circulatory system. Thermoreceptors can register the temperature of the skin and blood flow passing the hypothalamus and respond via thermoregulation $[23,24]$. These temperatures, however, are influenced by the integrated effect of all climatic parameters, which are in some kind of interrelation, i.e., influencing one another $[24,25]$. Based on the human energy balance, thermal indices can be derived, which describe the integral effect of weather, climate and climate change conditions on humans. All the thermal indices require the same meteorological input parameters: air temperature, air humidity, wind speed as well as the short- and long-wave radiation fluxes summarized as the mean radiant temperature (Tmrt) [9]. These input parameters show a temporal and spatial variability. Wind speed and mean radiant temperature show the highest variability and are strongly modified by surroundings and obstacles in complex urban areas. Results based on thermal indices show higher variability in the amplitude than those of air temperature only [12]. Easily understandable graphs and figures are an effective possibility for better communication among different users and disciplines [17]. 
Therefore, air temperature is not the only "singular" important parameter which can depict the overall effect of weather and climate conditions on human health. Such recognition is as important for present thermal risk factors, as they are when approaching climate change projections for the end of the century [26].

Commonly used thermal indices are the Physiologically Equivalent Temperature (PET) [24,27-29], Standard Effective Temperature (SET *) [30] or Outdoor Standard Effective Temperature (Out_SET *) [31], Perceived Temperature (PT) [32] and the Universal Thermal Climate Index (UTCI) [33]. A summary of the appropriate thermal indices, from hundreds of them, are summarized and quantified in several studies [9,34,35].

Single factors and modifications, based on new approaches concerning the reduction in UHI, have led to actions such as white roofs or painting surfaces or modifying their surface characteristics, focusing mostly on the reduction in the surface temperature, and in some cases, also in air temperature. An interesting example, which can describe the differences between two approaches, is the reflection of surfaces, and their different albedo levels. On the one hand, lighter and/or white/off-white surfaces increase reflection, which in turn reduces mostly surface temperature and less so the air temperature. On the other hand, the increased reflection of white surfaces increases the short-wave radiation and finally the mean radiant temperature. In several cases, this can be estimated as about 3 to $5 \mathrm{~K}$ in terms of PET and less than $0.5 \mathrm{~K}$ in air temperature as a result of reflection.

The assessment of UHI can also be achieved by using different meso- and microscale models with different spatial resolutions and by conducting exemplary measurements for case studies [12,36]. In addition, the analysis of long-term data can be a promising approach, including the evaluation of both warm and cold conditions [37]. These results can be interpreted and applied by urban management and urban planning [38]. It has to be mentioned that studies applying thermal indices (PET or UTCI), compared to studies based on air temperature only, disagree with these results [39]. For example, an increase in the albedo of horizontal and vertical urban surfaces can decrease air temperature. At the same time, it increases the values of PET due to increased shortwave reflection. This is a relevant issue not only during summer but throughout the year [18,40].

For adapting and mitigating UHI, some studies focus on the modification of urban structures, using reflective materials [41] or increasing evaporative cooling [42]. However, these studies are mostly focused on only some aspects of the energy budget of the urban areas and concentrate mostly on air temperature reduction. In addition, basic information on the effects of urban morphology (aspect ratio) and orientation must be considered, not only in terms of heat stress but also of thermal comfort and cold stress [3,20].

Planners demand spatial information as maps, which requires the transfer of point to continuous meteorological information. This can be carried out by the application of statistical methods, such as artificial neural networks or other multiple linear regressions $[3,43]$. The concept behind it is to combine known information at one single point (i.e., PET or air temperature) with information such as altitude, slope, aspect ratio, cold air flow, land use types, build-up area, SVF, thermal images, building volume or number of trees [3,44-47]. Based on the information for the known points, the statistical relationship is built and then transferred to the areas without primary information, hence facilitating the production of spatial urban bioclimatic information [2].

For many planning guidelines, information and results are needed, which have to fulfill requirements that are based on an overall approach in terms of annual conditions. Therefore, studies based only on day measurements and model simulations are extremely limited when aiming to provide planning considerations and information for guidelines. The supporting background information should always be described and stated, especially when it is for one simulation or based upon a singular parameter, including surface temperature and air temperature. The advantages and disadvantages of the used methodology or approach have to be clearly identified. This is not only important with regard to the results but also for their subsequent implementation within guidelines and/or policies. The provided information should rely not only on qualitative information but quantitative 
as well. Specific maps, which contain information on heat stress or hot spots, should also address the amount of occurrences, such as the annual number of times a specific or extreme condition takes place [2], with the following simple rules: how often issues can occur, and what the dangers and/or damages that can take place as a result are.

This begs the following question: what kinds of data are required and how can they be used in applications to other or related disciplines? When exploring this question, one must appreciate that a specific user, who may have a different background, may perceive the terminology used to depict the climatic parameter (e.g., air temperature or surface temperature) differently. Amongst other reasons, these depictions are strongly correlated to cultural and idiosyncratic characteristics that, in turn, can lead to different interpretations of the same word meaning. Nevertheless, communication must invariably be established via mutual understanding and the setup/application of clear definitions of terms and contents, in order to avoid "language confusion". Therefore, a set of common basic points, knowledge, exchange and common aims must be established.

Resembling something of an urban "myth" is that mitigation and/or adaptation measures within the urban fabric (not only painting white) are focused upon the reduction in air and surface temperature. While it is partially true, it frequently leads to misconception. Such a misapprehension is due to the fact that air temperature effects are limited to a small area, driven by the surface exchange, and subsequently presented by atmospheric synoptical circulation situations. For heat stress quantification, which is the foundation for thermal comfort studies, with the exception of air temperature, the most influencing factor is that of radiation, especially short-wave radiation (i.e., sun exposure) and long-wave fluxes of surfaces (i.e., wall heat emission and its convective exchange with encircling air temperature). For this very reason, while relationships between the human biometeorological system and radiation are different within indoor contexts, radiation still plays a fundamental role, given its unequivocal impact upon the very structures that accommodate human life for so many hours of the day. For this reason, and in unison with air temperature, radiation fluxes also play a significant role in the growing combat against heat stress-related morbidity and mortality within the built environment, particularly for the elderly and other vulnerable risk groups.

In addition, wind speed also plays a significant role in the instigation of thermal comfort conditions for humans, and in particular circumstances, upon structural elements via heat advection if surfaces are too warm. Yet, such effects ultimately return to influences upon indoor and outdoor human thermal comfort thresholds, either through the reduction in the long-wave emission of heat to the encircling microclimate [43], or the reduction in the subsequent conduction of energy (in the form of heat) into an interior setting via the building envelope.

An additional important factor is issues that can modify and improve the microclimate by sun protection; increase and optimize greenery; modify surfaces and material and water, including misting approaches [43]. A specific issue is the interactions with indoor contexts [47] and the effect of the modification of vertical facades [48] and the related human biometeorological quantification.

Nevertheless, it is instrumental to realize that both radiation fluxes and wind circulation dynamics are factors that can be modified within urban microscales through the implementation of thermal comfort sensitive urban planning and design measures. In an encompassing manner, the local encircling air in the urban canopy layer should be "focused on things that can be changed", instead of modifications leading to less significant modifications, which have smaller impacts upon human thermal comfort thresholds within the consolidated urban fabric. Overall, the aim here should be to effectively summarize and quantify factors which are the most crucial for the creation of more comfortable conditions in urban areas, based on existing targets and solutions, especially at the microscale [46].

An excellent and successful applied approach in one specific geographical or climate region can serve as a lesson or "benchmark", which can be applied to other cases and scenarios which present similar obstacles. Of course, such a "re-application" of knowledge 
must be handled carefully, and as a case-to-case methodology, recognizing their own local urban particularities and characteristics that have to be considered. To mention a few important analogies, amongst many other considerations, one must consider the amount of hot days and if the results obtained in another project are equitable for the new site and/or region (which should have moreover some comparable similarities in terms of scale, layout, amenities, and composition). In other words, both the physical properties and background climatic relatability must be appropriate when considering the application of a previous precedent that designers and/or decision makers are subsequently aspiring to [49]. An example of how heat stress can be approached and/or attenuated in South Germany or in the Mediterranean region does not represent, by any means, a generic solution which can be universally applied in other contexts, such as within a Northern European region. Nevertheless, there are still lessons which can be invaluable amid different climatic regions, which circumvent the case-to-case methodology. These invaluable lessons are those that portray devoted interdisciplinary action, which plays a fundamental role in instigating the international community to overcome uncertainty, inaction and contemplate how their own local and/or regional risk factors can be addressed. Such a mentality is among the driving forces of the maturing climate change adaptation agenda since the turn of the century.

Building upon the latter rational, to achieve results that likewise appeal to populations and inspire decision makers (including those within city administrations who may otherwise have different agenda priorities), showcasing international examples within the urban public realm can: (i) highlight the benefits of investing in such pressing agendas, both in the long-term socio-economic sense, but also in the ensuring of the long-term local "genius loci", which can be lost if they struggle to sustain outdoor comfortable environments; (ii) reduce the frequent apprehension in bottom-up approaches to tackle global issues by using science to back local decision making, therefore addressing local thermal risk factors to improve the quality of life for local and/or regional inhabitants of a respective urban context. For this reason, these kinds of examples are very helpful, because they include mostly the participation of local people and also several NGOs or environmental organizations. In addition, specific priorities can be set concerning applied methods and achievements of specific results, bearing in mind that the results should be reliable and applicable, and just as importantly, easily understandable/accessible in the context of presentation for non-specialists or experts [39]. Similar or related popular events, e.g., sport events, can be very effective here, because the same methods of presentation are applied and have strong media coverage. The best example is the transfer of the FIFA games 2022 from summer to winter [50] and the shift of specific outdoor games from Tokyo to Sapporo for the Olympic games in 2020 or 2021 [12,51,52].

For urban studies, which consider the urban bioclimate, the results and recommendations are mostly addressed to urban planners, with a focus on implementation. For this specific issue, the spatial resolution of requested information should be considered. It seems to be more appropriate that architects, urban designers and landscape architects should also be included in the process, and therefore, meet their requests for relevant spatial and temporal resolution maps. For this reason, while urban studies must continue to develop and refine their tools, methods and analyses of the urban climate, they must also deal with the aim of facilitating the communication and interpretation of these scientific outputs with those that will also play a pivotal role in directly shaping the contemporary urban fabric.

There are several additional issues that are important and require discussion. In many cases, it makes little sense to try to apply the inappropriate method and demand the application of models and results. In reality, and under such circumstances, they can instead produce less significant results, or incorrect results altogether, which are, respectively, either impossible to reproduce or not worth reproducing at all. Therefore, the slogan "less is more" and "right time and right place" are principles that should always be considered.

In addition, referring to the ancient Japanese ritual of "Uchimizu" as one single casein-point, it is also noteworthy that different climate regions, with long-lasting traditions 
and history, have not only different behaviors but also climate experience and solutions. These have been established over the eons and provide accurate and good solutions that have been adapted or adjusted to local or regional climate conditions [53-56].

Lastly, the regulations component is also an important issue. A very pertinent example of this is the constitution of recommendations for the construction of Heat Health Action Plans (HAPs) [57,58] not only for specific North American or European countries. They contain several factors, which must be successful applied and implemented, but also show how to combine and bring several experts and disciplines together [57,58]. For this reason, success is not solely dependent on the promotion of the HAPs but also on its inherent feature to enhance communication, not only for round tables but in a comprehensive application for protecting humans during heat waves and extreme heat conditions.

There are specific and general issues that have to be considered concerning the new situations and conditions in cities. In several approaches, the target should be clearly defined, and this should be the quality of life and protection of human health. The results and solutions should focus not only on qualitative but also quantitative results. Nonetheless, it is of the utmost importance to enable the communication and the adequate presentations of results and information. When sharing such information, one must take into account the typology of the audience, and reflecting this in the appropriate and adequate language, with easily understandable examples that reflect solutions which are technically and economically viable. Moreover, when such solutions are considered to be transposed into another area, both the climatic and urban contexts must be compatible and appropriate in order to avoid risks of "maladaptation". In this perspective, a terminology such as climate-orientated urban planning and design (including architectural issues) should help to provide interdisciplinary solutions among different professionals that must come together to resolve mutual points of interest in an era of climate change.

The final concept and approach can be summarized as follows: Target, Results, Information, Transfer/Communication, Implementation, Success (including monitoring and evaluation) (TRITIS).

Conflicts of Interest: The author declares no conflict of interest.

\section{References}

1. Müller, N.; Kuttler, W.; Barlag, A.-B. Counteracting urban climate change: Adaptation measures and their effect on thermal comfort. Theor. Appl. Climatol. 2014, 115, 243-257. [CrossRef]

2. Matzarakis, A.; Röckle, R.; Richter, C.; Höfl, H.; Steinicke, W.; Streifeneder, M.; Mayer, H. Planungsrelevante Bewertung des Stadtklimas. Umweltmeteorologie 2008, 68, 334-340.

3. Ketterer, C.; Matzarakis, A. Human-biometeorological assessment of heat stress reduction by replanning measures in Stuttgart, Germany. Landsc. Urban Plan. 2014, 122, 78-88. [CrossRef]

4. Schär, C.; Vidale, P.L.; Lüthi, D.; Frei, C.; Häberli, C.; Liniger, M.A.; Appenzeller, C. The role of increasing temperature variability in European summer heatwaves. Nature 2004, 427, 332-336. [CrossRef]

5. Chapman, S.; Watson, J.E.; Salazar, A.; Thatcher, M.; McAlpine, C.A. The impact of urbanization and climate change on urban temperatures: A systematic review. Landsc. Ecol. 2017, 32, 1921-1935. [CrossRef]

6. Matzarakis, A.; Paramita, B. Equity, Equality and Justice in Urban Housing Development; UPI Press: Bandung, Indonesia, 2018; pp. 1-327.

7. Landsberg, H.E. The Urban Climate; Academic Press: Cambridge, MA, USA, 1981.

8. Oke, T.R. The energetic basis of the urban heat island. Q. J. R. Meteorol. Soc. 1982, 108, 1-24. [CrossRef]

9. Staiger, H.; Laschewski, G.; Matzarakis, A. Selection of appropriate thermal indices for applications in human biometeorological studies. Atmosphere 2019, 10, 18. [CrossRef]

10. Oke, T.R. Canyon geometry and the nocturnal urban heat island: Comparison of scale model and field observations. J. Climatol. 1981, 1, 237-254. [CrossRef]

11. Matzarakis, A. Die thermische Komponente des Stadtklimas; Albert-Ludwigs-Universität Freiburg: Freiburg, Germany, 2001; pp. 1-287.

12. Matzarakis, A.; Fröhlich, D.; Bermon, S.; Adami, P.E. Quantifying Thermal Stress for Sport Events-The Case of the Olympic Games 2020 in Tokyo. Atmosphere 2018, 9. [CrossRef]

13. Matzarakis, A. A Note on the Assessment of the Effect of Atmospheric Factors and Components on Humans. Atmosphere 2020, 11, 1283. [CrossRef]

14. Oke, T.R.; Mills, G.; Christen, A.; Voogt, J.A. Urban Climates; Cambridge University Press: Cambridge, UK, 2017. 
15. Ketterer, C.; Matzarakis, A. Human-biometeorological assessment of the urban heat island in a city with complex topography The case of Stuttgart, Germany. Urban Clim. 2014, 10, 573-584. [CrossRef]

16. Matzarakis, A. Stadtklima vor dem Hintergrund des Klimawandels. Gefahrst. -Reinhalt. Der Luft 2013, 73, 115-118.

17. Matzarakis, A. Transfer of climate data for tourism applications-the climate-tourism/transfer-information-scheme. Sustain. Environ. Res. 2014, 24, 273-280.

18. Matzarakis, A.; Endler, C. Climate change and thermal bioclimate in cities: Impacts and options for adaptation in Freiburg, Germany. Int. J. Biometeorol. 2010, 54, 479-483. [CrossRef]

19. Matzarakis, A.; Fröhlich, D.; Ketterer, C.; Martinelli, L. Urban bioclimate and micro climate-How to construct cities in the era of climate change. In Climate Change and Sustainable Heritage; Meuwissen, J.M.C., Hofbauer, C.K., Kandjani, E.M., Eds.; 2018; pp. 38-61. Available online: https://www.researchgate.net/publication/323935446_URBAN_BIOCLIMATE_AND_MICRO_ CLIMATE-HOW_TO_CONSTRUCT_CITIES_IN_THE_ERA_OF_CLIMATE_CHANGE (accessed on 20 April 2021).

20. Herrmann, J.; Matzarakis, A. Mean radiant temperature in idealised urban canyons-examples from Freiburg, Germany. Int. J. Biometeorol. 2012, 56, 199-203. [CrossRef] [PubMed]

21. Fröhlich, D.; Matzarakis, A. Modeling of changes in thermal bioclimate: Examples based on urban spaces in Freiburg, Germany. Theor. Appl. Climatol. 2012, 111, 547-558. [CrossRef]

22. Mauree, D.; Coccolo, S.; Perera, A.T.D.; Nik, V.; Scartezzini, J.-L.; Naboni, E. A new framework to evaluate urban design using urban microclimatic modeling in future climatic conditions. Sustainability 2018, 10, 1134. [CrossRef]

23. Höppe, P.R. Heat balance modelling. Experientia 1993, 49, 741-746. [CrossRef]

24. Höppe, P. The physiological equivalent temperature-a universal index for the biometeorological assessment of the thermal environment. Int. J. Biometeorol. 1999, 43, 71-75. [CrossRef] [PubMed]

25. VDI Guideline 3787/Part 2. Bestimmung der mittleren Strahlungstemperatut - Anhang. In VDI/DIN Handbuch Reinhaltung der Luft Umweltmeteorologie; KRdL, K.R.d.L.i.V.u.D.N., Ed.; Beuth Verlag: Berlin, Germany, 1998.

26. Matzarakis, A.; Amelung, B. Physiological equivalent temperature as indicator for impacts of climate change on thermal comfort of humans. In Seasonal Forecasts, Climatic Change and Human Health; Springer: Berlin/Heidelberg, Germany, 2008 ; pp. 161-172.

27. VDI Guideline 3787/Part 2. Methoden zur human-biometeorologischen Bewertung von Klima und Lufthygiene für die Stadtund Regionalplanung. In VDI/DIN Handbuch Reinhaltung der Luft Umweltmeteorologie; KRdL, K.R.d.L.i.V.u.D.N., Ed.; Beuth: Berlin, Germany, 1998.

28. Mayer, H.; Höppe, P. Thermal comfort of man in different urban environments. Theor. Appl. Climatol. 1987, 38, 43-49. [CrossRef]

29. Matzarakis, A.; Mayer, H.; Iziomon, M.G. Applications of a universal thermal index: Physiological equivalent temperature. Int. J. Biometeorol. 1999, 43, 76-84. [CrossRef]

30. Gagge, A.P.; Fobelets, A.; Berglund, L. A standard predictive Index of human reponse to thermal enviroment. Trans./Am. Soc. Heat. Refrig. Air-Cond. Eng. 1986, 92, 709-731.

31. Spagnolo, J.; de Dear, R. A field study of thermal comfort in outdoor and semi-outdoor environments in subtropical Sydney Australia. Build. Environ. 2003, 38, 721-738. [CrossRef]

32. Staiger, H.; Laschewski, G.; Gratz, A. The perceived temperature - a versatile index for the assessment of the human thermal environment. Part A: Scientific basics. Int. J. Biometeorol. 2012, 56, 165-176. [CrossRef]

33. Jendritzky, G.; de Dear, R.; Havenith, G. UTCI-why another thermal index? Int. J. Biometeorol. 2012, 56, 421-428. [CrossRef]

34. Binarti, F.; Koerniawan, D.; Triyadi, S.; Utami, S.S.; Matzarakis, A. A review of outdoor thermal comfort indices and neutral ranges for hot-humid regions. Urban Clim. 2020, 31. [CrossRef]

35. Potchter, O.; Cohen, P.; Lin, T.-P.; Matzarakis, A. Outdoor human thermal perception in various climates: A comprehensive review of approaches, methods and quantification. Sci. Total Environ. 2018, 631-632, 390-406. [CrossRef]

36. Fröhlich, D.; Matzarakis, A. Spatial Estimation of Thermal Indices in Urban Areas-Basics of the SkyHelios Model. Atmosphere 2018, 9. [CrossRef]

37. Bauche, J.P.; Grigorieva, E.; Matzarakis, A. Human-Biometeorological Assessment of Urban Structures in Extreme Climate Conditions: The Example of Birobidzhan, Russian Far East. Adv. Meteorol. 2013, 2013, 1-10. [CrossRef]

38. Thwaites, K.; Porta, S.; Romice, O.; Greaves, M. Urban Sustainability through Environmental Design: Approaches to Time-People-Place Responsive Urban Spaces; Taylor \& Francis: Abingdon, UK, 2007.

39. Fröhlich, D.; Matzarakis, A. Modeling of Changes in Human Thermal Bioclimate Resulting from Changes in Urban Design: Example Based on a Popular Place in Freiburg, Southwest Germany. In Advances in Meteorology, Climatology and Atmospheric Physics; Helmis, C., Nastos, P., Eds.; Springer Atmospheric Sciences: Berlin/Heidelberg, Germany, 2013; pp. $443-449$.

40. Knez, I.; Thorsson, S.; Eliasson, I.; Lindberg, F. Psychological mechanisms in outdoor place and weather assessment: Towards a conceptual model. Int. J. Biometeorol. 2009, 53, 101-111. [CrossRef]

41. Lin, T.-P.; Matzarakis, A.; Hwang, R.-L.; Huang, Y.-C. Effect of pavements albedo on long-term outdoor thermal comfort. Ber. Des Meteorol. Inst. Der Albert-Ludwigs-Univ. Freibg. 2010, 497.

42. Akbari, H. Cooling Our Communities. A Guidebook on Tree Planting and Light-Colored Surfacing; United States Environmental Protection Agency: Washington, DC, USA, 1992.

43. Ketterer, C.; Matzarakis, A. Mapping the Physiologically Equivalent Temperature in urban areas using artificial neural network. Landsc. Urban Plan. 2016, 150, 1-9. [CrossRef] 
44. Martinelli, L.; Matzarakis, A. Influence of height/width proportions on the thermal comfort of courtyard typology for Italian climate zones. Sustain. Cities Soc. 2017, 29, 97-106. [CrossRef]

45. Abreu-Harbich, L.V.; Labaki, L.C.; Matzarakis, A. Thermal bioclimate in idealized urban street canyons in Campinas, Brazil. Theor. Appl. Climatol. 2014, 115, 333-340. [CrossRef]

46. Santos Nouri, A.; Costa, J.; Santamouris, M.; Matzarakis, A. Approaches to Outdoor Thermal Comfort Thresholds through Public Space Design: A Review. Atmosphere 2018, 9. [CrossRef]

47. Manzano-Agugliaro, F.; Montoya, F.G.; Sabio-Ortega, A.; García-Cruz, A. Review of bioclimatic architecture strategies for achieving thermal comfort. Renew. Sustain. Energy Rev. 2015, 49, 736-755. [CrossRef]

48. Jänicke, B.; Meier, F.; Hoelscher, M.-T.; Scherer, D. Evaluating the effects of façade greening on human bioclimate in a complex urban environment. Adv. Meteorol. 2015, 2015. [CrossRef]

49. Yang, S.-Q.; Matzarakis, A. Implementation of human thermal comfort information in Koppen-Geiger climate classification-the example of China. Int. J. Biometeorolgy 2016, 60, 1801-1805. [CrossRef] [PubMed]

50. Matzarakis, A.; Frohlich, D. Sport events and climate for visitors-the case of FIFA World Cup in Qatar 2022. Int. J. Biometeorol. 2015, 59, 481-486. [CrossRef]

51. Wu, Y.; Graw, K.; Matzarakis, A. Comparison of thermal comfort between Sapporo and Tokyo-the case of the Olympics 2020. Atmosphere 2020, 11, 444. [CrossRef]

52. Matzarakis, A.; Fröhlich, D.; Bermon, S.; Adami, P. Visualization of Climate Factors for Sports Events and Activities-The Tokyo 2020 Olympic Games. Atmosphere 2019, 10. [CrossRef]

53. Rodríguez Algeciras, J.A.; Gómez Consuegra, L.; Matzarakis, A. Spatial-temporal study on the effects of urban street configurations on human thermal comfort in the world heritage city of Camagüey-Cuba. Build. Environ. 2016, 101, 85-101. [CrossRef]

54. Rodríguez-Algeciras, J.; Rodríguez-Algeciras, A.; Chaos-Yeras, M.; Matzarakis, A. Tourism-related climate information for adjusted and responsible planning in the tourism industry in Barcelona, Spain. Theor. Appl. Climatol. 2020, 142, 1003-1014. [CrossRef]

55. Rodriguez Algeciras, J.A.; Matzarakis, A. Quantification of thermal bioclimate for the management of urban design in Mediterranean climate of Barcelona, Spain. Int. J. Biometeorolgy 2016, 60, 1261-1270. [CrossRef]

56. Rodríguez-Algeciras, J.; Tablada, A.; Chaos-Yeras, M.; De la Paz, G.; Matzarakis, A. Influence of aspect ratio and orientation on large courtyard thermal conditions in the historical centre of Camagüey-Cuba. Renew. Energy 2018, 125, 840-856. [CrossRef]

57. Straff, W.; Mücke, H.-G.; Baeker, R.; Baldermann, C.; Braubach, A.; Litvinovitch, J.; Matzarakis, A.; Petzold, G.; Rexroth, U.; Schroth, S. Handlungsempfehlungen für die Erstellung von Hitzeaktionsplänen zum Schutz der menschlichen Gesundheit. Bundesgesundheitsblatt-Gesundh.-Gesundh. 2017, 60, 662-672. [CrossRef]

58. Zielo, B.; Matzarakis, A. Bedeutung von Hitzeaktionspläne für den präventiven Gesundheitsschutz in Deutschland. Gesundheitswesen 2017, 79. [CrossRef] 